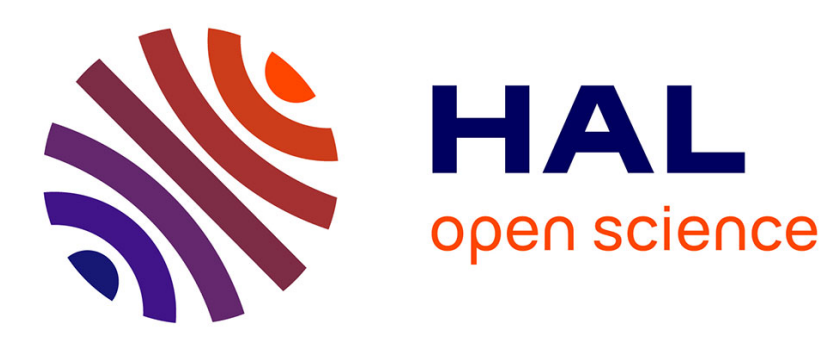

\title{
Detection of Ground Movement using the Shape of Brillouin Spectrum
}

\author{
Edouard Buchoud, Sylvain Blairon, Guy d'Urso, Jean-Marie Henault, \\ Alexandre Girard, Jerome I. Mars, Valeriu Vrabie
}

\section{- To cite this version:}

Edouard Buchoud, Sylvain Blairon, Guy d'Urso, Jean-Marie Henault, Alexandre Girard, et al.. Detection of Ground Movement using the Shape of Brillouin Spectrum. 18th European Meeting of Environmental and Engineering Geophysics, Sep 2012, Paris, France. pp.B32. hal-00728409

\section{HAL Id: hal-00728409 \\ https://hal.science/hal-00728409}

Submitted on 5 Sep 2012

HAL is a multi-disciplinary open access archive for the deposit and dissemination of scientific research documents, whether they are published or not. The documents may come from teaching and research institutions in France or abroad, or from public or private research centers.
L'archive ouverte pluridisciplinaire HAL, est destinée au dépôt et à la diffusion de documents scientifiques de niveau recherche, publiés ou non, émanant des établissements d'enseignement et de recherche français ou étrangers, des laboratoires publics ou privés. 

of Brillouin Spectrum

\author{
E Buchoud* (EDF), S. Blairon (EDF), G. D'urso (EDF), J.M. Henault (EDF), A. \\ Girard (EDF), J. Mars (GIPSA-LAB) \& V. Vrabie (CRESTIC Reims)
}

\title{
SUMMARY
}

Distributed Optical Fiber Sensing systems (DOFSS) are composed by optical fibers wrapped in strain sensing cables, coupled with Brillouin interrogators. DOFSS are increasingly used for Structural Health Monitoring (SHM) as they can provide continuous strain profiles along the optical fiber localized in the structure. Raw Brillouin measurements consist in gain - frequency curves with a Lorentzian shape. Strain is generally assessed thanks to the abscissa of the maximum of the gain curve. Two new factors are introduced. They are sensitive to asymmetry and broadening of the Brillouin gain curve which can highlight strain gradient within the spatial resolution of the interrogator. These parameters could be used to detect more efficiently local events and improve instrument algorithm. 


\section{$\underset{\text { Geoscience } 2017}{\text { Near Surface }}$}

\section{Introduction}

For the needs of its hydroelectric power plants, EDF (Electricité de France) operates geotechnical civil structures such as dams and dikes. Their durability and stability is a crucial issue that affects maintenance optimization, safety, and availability of the structures. Some of these structures suffer from long effects, such as internal erosion, which could provoke water leakage or embedded cavities. As a complement with conventional sensors, Distributed Fiber Optic Sensing Systems (DOFSS) have shown to be an attractive tool but many challenges are still opened (Lanticq et al. (2009), Mars et al. (2010)).

DOFSS is composed by an optical fiber sensing cable and an optoelectronic device. It enables to get strain or temperature profiles all along the fiber by using backscattering phenomena in silica like Rayleigh and Brillouin scattering (temperature and strain-sensitive) or Raman scattering (temperaturesensitive).

To ensure that DOFSS fits EDF applications needs, a "from the lab to the field" methodology is conducted to qualify the measuring system (Hénault et al. (2010)). This abstract focuses on the measuring results obtained during a laboratory test with optical fiber sensing cables embedded into a one-to-one scale soil structure exposed by Blairon et al. (2011). Rayleigh and Brillouin devices were used to measure strain profiles along the cables. Rayleigh instrument provides detailed strain profiles, with a centimetre spatial resolution, which could be considered as a reference. Brillouin instrument provides a data matrix composed by a gain - frequency curve for each spatial resolution segment (1m). The device determines automatically the strain profiles thanks to the abscissa of the maximum of the gain curves. Ravet et al. (2006) showed that Brillouin gain curves could be distorted by local non uniform strain distribution along the fiber. In this paper, two new factors are defined so as to highlight asymmetry and broadening of the Brillouin gain curves. We demonstrate that these factors could be used to detect and localize strain gradients along the fiber within the spatial resolution of the device.

\section{Optoelectronic devices}

Two types of optoelectronic devices were used:

- An instrument based on the optical Rayleigh backscattering analysis performed by an Optical Frequency Domain Reflectometry (OFDR) technique named OBR (Optical Backscattered Reflectometer),

- Another one based on the analysis of Brillouin backscattering phenomena using Optical Time Domain Reflectometry (OTDR) and called B-OTDA (Brillouin Optical Time Domain Analyzer).

OBR working principles are detailed in Frogatt et al. (1998). The OBR correlates two OFDR traces then converts the spectral shift into strain assuming a linear dependency. An advantage of this instrument is to provide a centimeter spatial resolution strain profile. However, its distance range is less than a hundred meter. Therefore, this device is adapted for the study of mock-up for geotechnical civil applications, but can't be used on field. In this study, the OBR is considered as our reference in order to detect local strain gradients along the sensing cable.

B-OTDA is based on the principle of stimulated Brillouin scattering (SBS). When a light pulse is launched into an optical fiber, a small part of it is frequency shifted. Further information can be found in Bao et al. (1995). For each acquisition, B-OTDA generates a data matrix giving Brillouin gain depending on frequency and distance. Zou et al. (2005) showed that Brillouin spectra, for B-OTDA, have a Lorentzian shape. From this matrix, a Brillouin frequency shift profile $v_{B}(z)$ could be found for a state of the optical fiber. For each $\mathrm{z}, v_{B}(z)$ corresponds to the abscissa of the maximum of the frequency gain curve, determined by best fitting, in terms of the L2 norm, with a symmetric Lorentzian function..

The Brillouin frequency shift $v_{\mathrm{B}}$, is linearly related to the strain and temperature conditions along the fiber optic (Nikles et al. (1997)). The instrument performs a relative profile strain measurement (Figure 1.b.) comparing Brillouin frequency shifts between two states of the sensing cable: 


\section{Near Surface

$$
v_{B}(z)=v_{B 0}(z)+C_{T} \Delta T(z)+C_{\varepsilon} \varepsilon(z)
$$

with $v_{B 0}(z)$ the Brillouin frequency in the first state, and $v_{B}(z)$ the frequency measured in the actual state. At the operating wavelength $\left(1550 \mathrm{~nm}\right.$ in our cases), for standard single-mode fiber, $C_{T}$ and $C_{\varepsilon}$ are in the order of $1 \mathrm{MHz} /{ }^{\circ} \mathrm{C}$ and $0.05 \mathrm{MHz} / \mu \varepsilon$. In our study, temperature is constant. Strain is directly deduced from deduced from (1).

\section{Description of the laboratory experiment}

The laboratory experiment aimed at studying distributed strain sensing chain (see details in Blairon et al. (2011)). The mock-up configuration is presented in Figure 1.a. Two interrogators, OBR and BOTDA are used.

Underground cavities were generated using hydraulic controlled actuators under a sand soil. Several vertical displacements, from $2 \mathrm{~mm}$ to $10 \mathrm{~mm}$ stepped each $2 \mathrm{~mm}$ were imposed. An example of Brillouin matrix is shown in Figure 1b, with a spatial resolution of $1 \mathrm{~m}$ and an over-sampling of $40 \mathrm{~cm}$, for a specific cable, , for a piton displacement of $4 \mathrm{~mm}$ downward. Figure 1c shows strain coherent assessments given by B-OTDA (blue) and OBR (red). Different areas are distinguished: two of them are traction zones, where strain is positive; one of them is a compression zone, where strain is negative. These zones are characterized by existing strain gradients over an extension of about $4 \mathrm{~m}$, centered on the piton position.

a
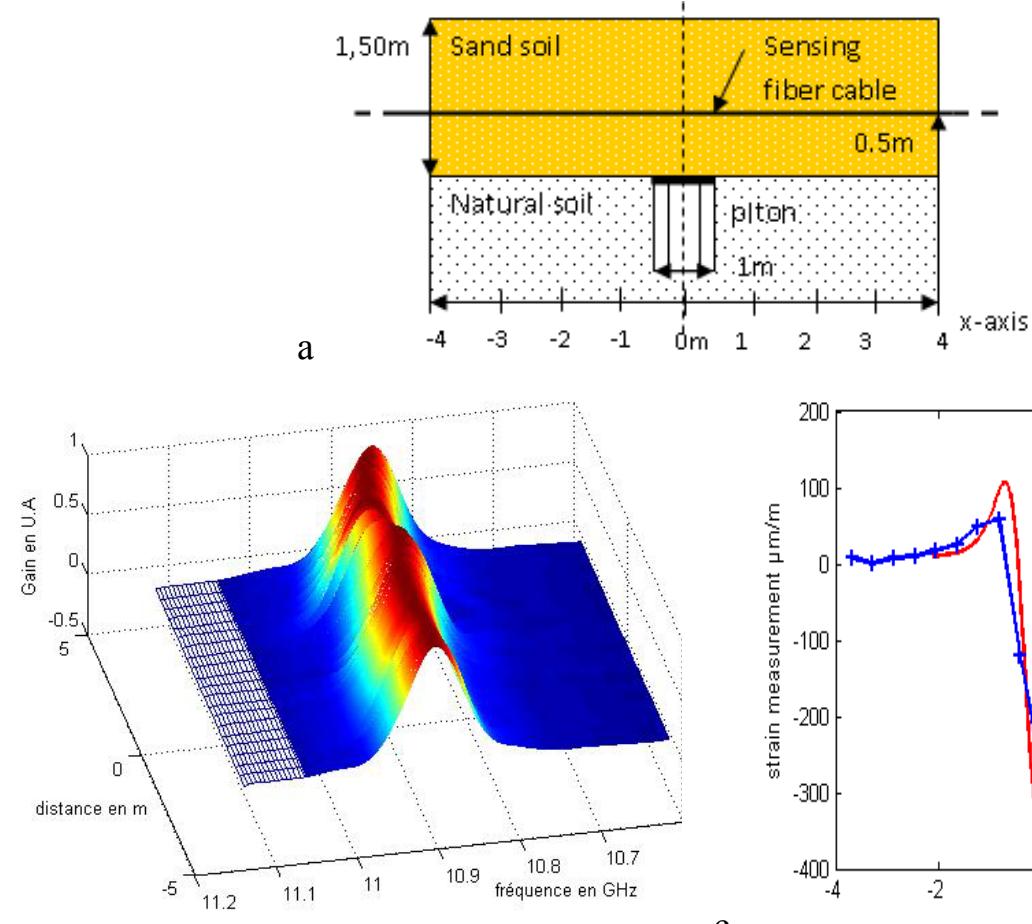

b.

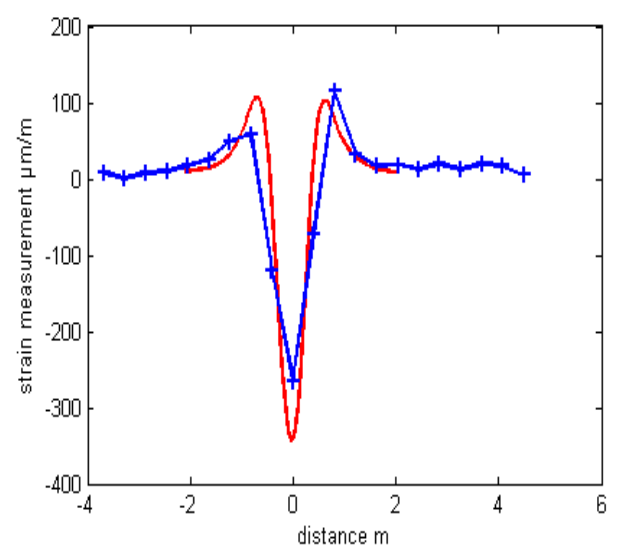

Figure 1 a. Schematic side-view of the 1-1scale laboratory experiment with embedded cable; $b$. Example of a Brillouin matrix acquired with the B-OTDA for a piton displacement of $4 \mathrm{~mm} ; \mathrm{c}$. Strain profiles acquired withB-OTDA (blue) and OBR (red).

\section{Brillouin shape factors}

Ravet et al. (2006) showed that non-uniform strain distribution, like cracks, influences Brillouin spectra shape. Two form factors were defined to detect distortion of Brillouin spectrum: asymmetry $F A(z)=\frac{\Gamma_{+}}{\Gamma_{-}}$and broadening $F B(z)=\frac{\Gamma_{+}+\Gamma_{-}}{\Gamma_{s}} . \Gamma_{-}$and $\Gamma_{+}$represent respectively right and left half full width at half maximum (FWHM) while $\Gamma s$ is defined as Brillouin line width. We define 
complementary asymmetric and broadening form factors: $R A i(z)=\frac{R_{+}}{R_{-}}$and $R B(z)=\frac{R_{s}}{R_{+}+R_{-}}$. The $R_{+}$represents the area of the left side of the Brillouin spectrum, computed from its base to the half of its height. The $R_{-}$is computed in the similar way for the right side, while $R_{s}$ represents the area of the above half height. Because of the limited place, we will only compare in this article the asymmetric factors RAi and FA.
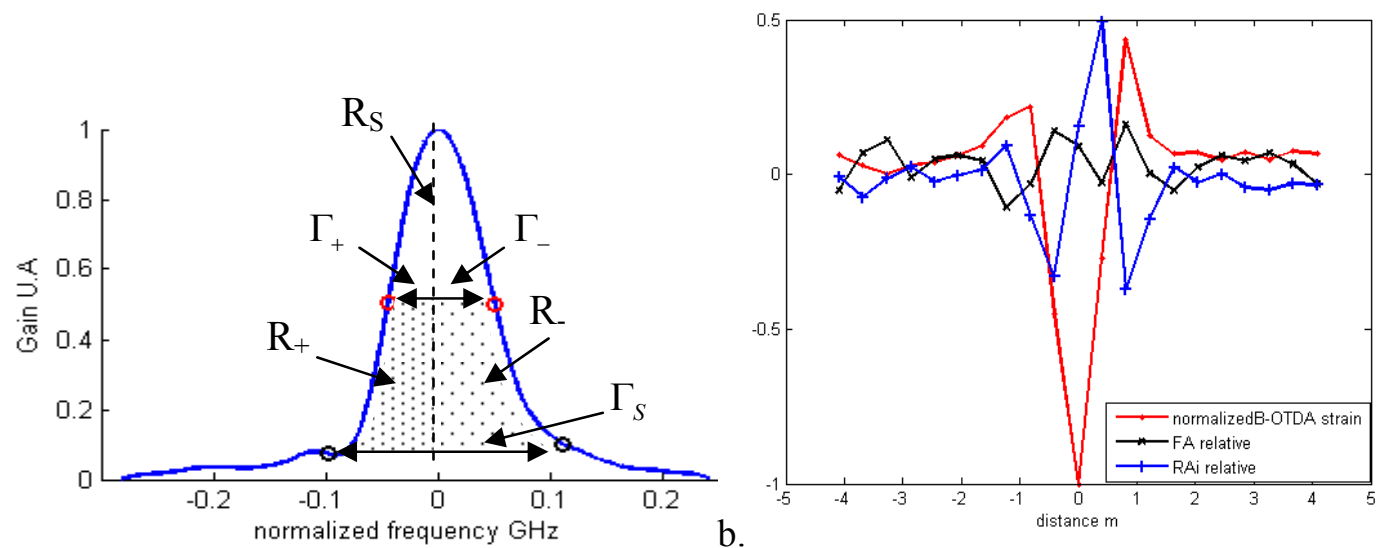

a.
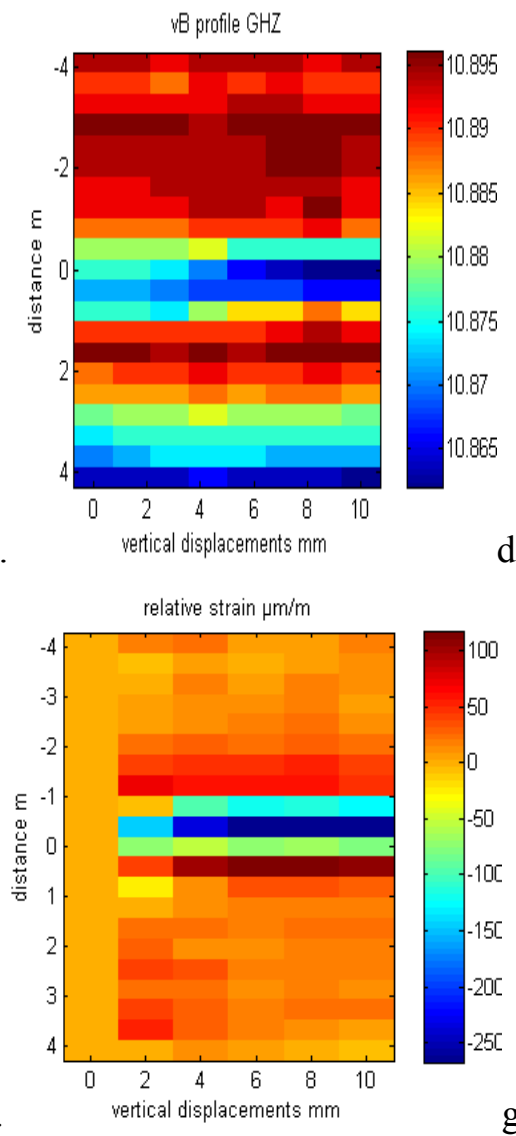
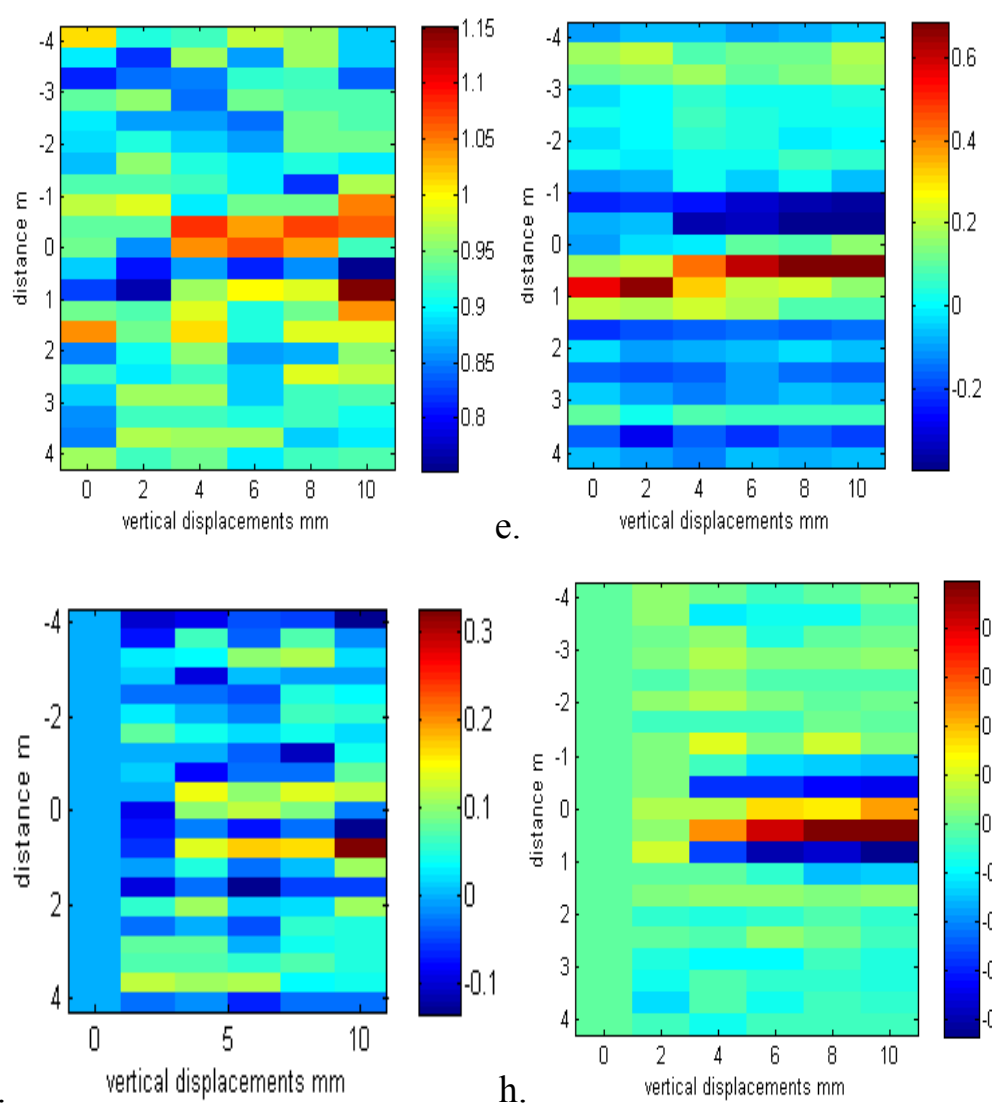

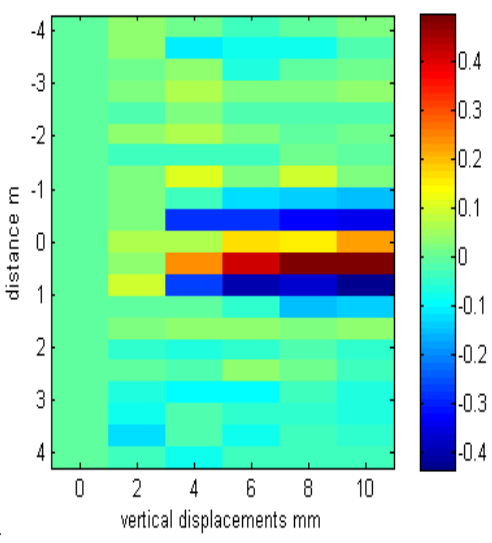

Figure 2 a. Definition of parameters on the gain curve; $b$. RAi, FA and B-OTDA strain profile for $a$ vertical displacement of $4 \mathrm{~mm} ; c . v_{B}(z)$ estimated by the B-OTDA device. d. FA evolution as function of distance and vertical displacements; $e$. RAi evolution depending on distance and vertical displacement in mm; $f$. B-OTDA strain assessment relative to zero displacement $g$. FA evolution relative to zero displacement; $h$. RAi evolution relative to zero displacement. 


\section{Near Surface \\ Geoscience 2012}

We have computed all these form factors on the Brillouin gain matrices shown in Figure 1.b. $v_{\mathrm{B}}$, RAi and FA profiles are illustrated on Figures $2 \mathrm{c}$ to $2 \mathrm{e}$. These parameters are sensitive to the piton displacement. To go further, as shown on Figures $2 \mathrm{f}$ to $\mathrm{h}$, the sensitivity is enhanced by the substraction of their initial profiles obtained for no displacement of the piton. For a $4 \mathrm{~mm}$ displacement, $v_{B}, R A i$ and FA relative profiles are illustrated on Figures $2 b$.

$\Delta \mathrm{v}_{\mathrm{B}}$ seems to be the most sensitive parameter to detection of strain along the fiber. FA is demonstrated to be not adapted to our case study. But, RAi could be used, in a complementary way, to detect strain gradient within the spatial resolution of the instrument.

\section{Conclusion}

Our approach is based on definition of Brillouin shape factors sensitive to symmetry and broadening of Brillouin spectrum. They could be used to detect strain evolution within the spatial resolution of the Brillouin instrument, complementary to measured strain profiles.

This result could lead to make the Brillouin instrument algorithm evolve to improve strain detection. These shape factors could be integrated in the $v_{B}$ determination using a special Lorentzian asymmetric function. Our future studies will be focused on the quantification of the strain gradient thanks to those factors and on the Brillouin spectrum decomposition to improve strain measurement.

\section{References}

Blairon, S., Hénault, J-M., Buchoud, E., Vinceslas, G., Delepine-Lesoille, S. [2011] Truly distributed optical fiber extensometers for geoptechnical structure monitoring (dikes and underground repository): Influence of sensor external coating. FMGM Expanded Abstract.

Bao, X., Dhliwayo, J., Heron, N., Webb, D.J. and Jackson, D.A. [1995] Experimental and theorical studies on a distributed temperature sensor based on Brillouin scattering. Journal of Lightwave Technology, 13(7).

Frogatt, M. and Moore, J. [1998] High-spatial-resolution distributed strain measurement in optical fiber with Rayleigh scatter. Applied Optics, 37(10).

Henault, J.M., Moreau, G., Blairon, S., Salin, J., Courivaud, J.R., Taillade, F., Merliot, E., Dubois, J.P., Bertrand, J., Buschaert, S., Mayer, S. and Delepine-Lesoille, S. [2010] Truly distributed optical fiber sensors for structural health monitoring: from the telecommunication optical fiber drawling tower to water leakage detection in dikes and concrete structure strain monitoring. Advances in Civil Engineering; 930796.

Lanticq, V., Gabet, G., Taillade, F., Delepine-Lesoille, S. [2009] Distributed Optical fiber sensors for structural health monitoring: upcoming challenges, chapter 9, in "Optical Fiber, New Developments".

Nikles, M., Thevenaz, L., Robert, P.A. [1997] Brillouin gain spectrum characterization in single-mode optical fibers. Journal of Ligthwave technology, 15(10).

Mars, J.I ., Khan, A.A., Vrabie, V., Girard, A. and Durso, G. [2010] Water Leakage Detection in Dikes by Fiber Optic, 72nd EAGE Conference \& Exhibition incorporating SPE EUROPEC 2010, Barcelona (2010).

Ravet, F., Bao, X., Ozbakkaloglu, T. and Saatcioglu, M. [2006] Signature of Structure Failure Using Asymmetric and Broadening Factors of Brillouin Spectrum. IEEE Photonics Technology Letters, 18(2).

Zou, L., Bao, X., Wan, Y. and Chen, L. [2005] Coherent probe-pump-based Brillouin sensor for centimeter-crack detection. OPTICS LETTERS, 30(4). 